\section{Speed-Accuracy Tradeoff}

Molly E. Zimmerman

Department of Psychology, Fordham University, Bronx, NY, USA

\section{Definition}

The complex relationship between an individual's willingness to respond slowly and make relatively fewer errors compared to their willingness to respond quickly and make relatively more errors is described as the speed-accuracy tradeoff.

\section{Current Knowledge}

In experimental studies of human performance, both the speed at which an individual completes a task and the accuracy of their response rates are important considerations in methodological study design as well as in the interpretation of findings. Ideally, an individual attempts to maximize performance on both factors. In some situations, however, an individual may increase his or her response time at the cost of reducing the accuracy of his or her responses, while in other situations an individual may find it necessary to slow his or her response time in order to increase his or her overall accuracy level (Proctor and Vu 2003). In experimental research, illustrative schematics of speedaccuracy tradeoff data reveal consistent relationships across many different tasks. Following the basic principal that it takes time for an individual to process information accurately, consideration of the speed-accuracy tradeoff is often undertaken to determine the minimum amount of time that is required to produce a correct response on a given task (Bullinaria 2000). This information has critical implications for overall experimental design as well as interpretation of results.

The implications of the speed-accuracy tradeoff for clinical neuropsychological assessment are implicit in test procedures which are timed or have time limits. When the patient is aware of the time component of the scoring system, he or she may attempt to maximize either the speed or the accuracy. Careful behavioral observation as well as a debriefing interview process may help elucidate the patient's strategy, thereby aiding in the interpretation of the test results.

\section{References and Readings}

Bullinaria, J. A. (2000). Free gifts from connectionist modeling. In R. Baddeley, P. J. B. Hancock, \& P. Foldiak (Eds.), Information theory and the brain (pp. 221-240). Cambridge: Cambridge University Press.

Proctor, R. W., \& Vu, K.-P. L. (2003). Action selection. In A. F. Healy \& R. W. Proctor (Eds.), Experimental psychology (pp. 293-316). Vol. 4 in I. B. Weiner (Editor-in-Chief) Handbook of psychology. New York: Wiley. 